ORIGINAL ARTICLE

\section{Simvastatin improves survival and reduces leukocyte recruitment and hepatocyte apoptosis in endotoxin- induced liver injury}

\author{
ABSTRAKT \\ BACKGROUND. Endotoxemia provokes excessive host response to bacteria or microbial \\ compounds, resulting in systemic inflammation, organ injury and mortality. \\ Aim: This study examined the effects of simvastatin on survival and liver injury in \\ endotoxic shock in a rat model of endotoxemia. \\ METHODS. Male Wistar rats were injected intraperitoneally with E.coli- \\ lipopolysaccharide (LPS) and the medial lethal dose $\left(L_{50}\right)$ was determined. \\ Simvastatin was given orally (5-40 mg/kg body weight) for five days prior to either \\ a single $L D_{50}$ dose of LPS or 2, 2.5 or $3 x L_{50}$. Liver damage was assessed by \\ histological examination and expressed as a tissue damaged score (TDS). Another \\ group of rats was treated with simvastatin and then challenged with LPS to determine \\ the degree of apoptosis in hepatocytes, liver immune cells, and cleaved caspase-3 \\ activity after $24 \mathrm{~h}$ of endotoxemia. \\ RESULTS. Endotoxemia caused substantial mortality with assiciated leukocyte \\ infiltration, liver injury (TDS $=3.67, \mathrm{SD}=0.55$ ), as well as notable apoptosis of \\ hepatocytes and resident liver macrophages. Simvastatin, in a dose-dependent \\ manner significantly reduced LPS-induced mortality, hepatocellular damage (TDS = \\ $1.5, \mathrm{SD}=0.55)$, inflammatory infiltration, and dte drug markedly decreased apoptosis \\ and expression of cleaved caspase-3. \\ Conclusions. Simvastatin improves survival in endotoxic shock and prevents \\ endotoxemic liver injury by inhibiting leukocyte infiltration and hepatocellular \\ apoptosis. These results suggest that simvastatin could be used to prevent \\ endotoxemia-associated liver dysfunction by simvastatin.
}

\section{KEY WORDS}

simvastatin, liver injury, endotoxin, inflammation, apoptosis
L. Nežić ${ }^{1}, \mathbf{L j}$. Amidžiće ${ }^{2}$. Jaćević, ${ }^{3}$ S. Dobricín, $R$. Škrbicí, M. P. Stojiljković, J. Komićs ${ }^{5}$ S. StoisavljevićŠatara ${ }^{1}$

${ }^{1}$ Department of Pharmacology, Toxicology and Clinical Pharmacology, Medical Faculty, Banja Luka; ${ }^{2}$ Department of Pathology, Clinical Center Banja Luka, Republic of Srpska, Bosnia and Herzegovina; ${ }^{3}$ National Poison Control Centre, Medical Military Academy, Crnotravska 11, 1100 o Belgrade, Serbia, ${ }^{4}$ Department of Pharmacology, Medical Faculty, University of East Sarajevo, 51000 Foča, Republic of Srpska, Bosnia and Herzegovina; ${ }^{5}$ Department of Statistics, Faculty of Economics, University of Banja Luka, Republic of Srpska, Bosnia and Herzegovina.

\author{
Correspondence \\ Lana Nežić, MD, MSc \\ Zavod za farmakologiju, toksikologiju \\ i kliničku farmakologiju \\ Medicinski fakultet \\ Save Mrkalja 14 \\ 78000 Banja Luka \\ Republic of Srpska \\ Bosnia and Herzegovina \\ Phone: +38751214 117 \\ E-mail: lanne@doctor.com
}

Submitted: April 30, 2011

Accepted: May 26, 2011

(Scr Med 2011;42:7-13)

Sepsis is a leading cause of death among critically ill patients. Despite extensive investigation over the past three decades, the incidence of sepsis and sepsis-related deaths is increasing. ${ }^{1}$ Endotoxin or lipopolysaccharide (LPS), the dominant portion of the outer membrane of Gram-negative bacteria, activates the inflammatory cells and increases production of pro-inflammatory cytokines including tumor necrosis factor alpha (TNF- $\alpha$, and other factors, such as nitric oxide (NO). ${ }^{2-4}$ Excessive production of proinflammatory mediators, by the host in response to LPS challenge results in systemic inflammation, tissue injury and organ failure, events that are strongly associated with septic shock. ${ }^{5}$ The relative severity of sepsis depends upon the balance between pro-inflammatory and anti-inflammatory states. Liver failure is an insidious problem for critically ill patients. Numerous studies suggest that hepatic infiltration of leukocytes as a cause of endotoxemic liver damage. ${ }^{6-7}$ The recruitment process of leukocytes in venules is a multistep process, involving adhesion of rolling leukocytes via a selectin-mediated mechanism, ${ }^{8,9}$ although leukocyte trapping in hepatic sinusoids occurs without of this interaction..$^{10}$ Contact between the lymphocyte function antigen-1 (LFA-1) and a family members of adhesive molecules expressed on endothelial cells firmly establishes leukocyte adhesion in the liver microvascular endothelium in endotoxemic mice. ${ }^{11}$ Transendothelial migration and tis- 
sue accumulation of leukocytes in the liver depend upon the formation of chemokines in hepatocytes. Once established within the extravascular parenchyma, these accumulated leukocytes promote hepatocellular apoptosis, resulting ultimately in liver failure.

Statins, or 3-Hydroxy-3-methylglutaryl coenzyme A (HMG-CoA) reductase inhibitors have had a major impact on healthcare by decreasing cardiovascular events. The efficacy of statins has been attributed primarily to their lipidlowering properties. However, a growing body of evidence highlights statin actions independent of its lipid-lowering properties. $^{12,13}$ These include anti-inflammatory and antioxidant effects. As a result, recently issued, a guideline recommends that patients with diabetes and cardiovascular disease should initiate statin therapy regardless of baseline LDL cholesterol levels. ${ }^{14}$ Retrospective and prospective observational studies indicate that that statin treatment reduces the incidence and mortality of sepsis, although not all investigators agree. ${ }^{15}$ Prospective clinical trials are currently evaluating the safety and efficacy of statins in septic patients. Along with these observational studies in humans, ${ }^{15}$ mouse models of sepsis and endotoxemia also indicate the protective actions of statins, which reportedly reduce mortality, preserve cardiac function, ameliorate inflammation and improve bacterial clearance. ${ }^{5,16}$ It is not yet known if these beneficial effects will obtain as well in endotoxemic liver injury.

We used a well-known rat model for endotoxemia to determine if oral simvastatin, could improve survival in endotoxic shock and prevent endotoxin-induced leukocyte recruitment, hepatocellular apoptosis and liver injury.

\section{Materials and Methods}

Animals. Experiments were performed on male Wistar rats, 6 - 8 weeks old (18o to 220 g body weight - b.w) bred at the Farm for Experimental Animals, Military Medical Academy, Belgrade, Serbia, and kept in the animal unit 7 days before the experiment. They were housed in plastic cages, under standard laboratory conditions $\left(21-22^{\circ} \mathrm{C}, 12\right.$ $\mathrm{h}$ light/dark cycle, $30-70 \%$ relative humidity). They were supplied with commercial food and tap water ad libitum. The animals were deprived of food $18-20 \mathrm{~h}$ before beginning of experiments with free access to tap water. Experimental groups consisted of six animals each. The study protocol was based on the Guidelines for Animal Study no. 282-12/2002 (Ethics Committee of the Military Medical Academy, Belgrade, Serbia).

Pharmacological Interventions. Simvastatin (Krka, Novo Mesto, Slovenia) was dissolved in $0.5 \%$ methylcellulose (Sigma, Taufkirchen, Germany), as 10 or $20 \mathrm{mg} / \mathrm{mL}$ stocks. Endotoxin from E. coli serotype 0127:B8 (Sigma Aldrich, Germany) was injected intraperitoneally (i.p.) after dilution with sterile pyrogen-free physiologic saline solution, in a volume of $1 \mathrm{~mL} / \mathrm{kg}$.
Endotoxin-induced lethality in rats. The animals were divided into three groups ( $n=6$ per group), given saline orally (p.o.) and challenged i.p with one of the three doses of LPS $(10,20,30 \mathrm{mg} / \mathrm{kg}$ b.w.). The lethality and changes in body temperature were then monitored over the next 7 days. Mortality resulting from LPS was recorded and the median lethal dose $\left(\mathrm{LD}_{50}\right)$ of LPS i.p. was calculated. ${ }^{17}$

Protective effects of of simvastatin on mortality induced by lethal dose of endotoxin. To establish the effect of shortterm pretreatment of simvastatin on the survival of rats injected with $\mathrm{LD}_{50}$ of LPS, the animals were divided into four groups ( $n=6$ per group); simvastatin was given p.o. in one of the four doses $(5,10,20$ and $40 \mathrm{mg} / \mathrm{kg}$ b.w, respectively) per day for 5 days. One and a half $h$ after the last dose of simvastatin the single $\mathrm{LD}_{50}$ of LPS was injected i.p. Control group was treated with saline for 5 days, before a single $\mathrm{LD}_{50}$ of LPS was injected. The rates of survival of animals and changes in body temperature were monitored for a period of 7 days.

The doses of simvastatin in our study were comparable to those that had previously been used in rat/murine studies in vivo (typically $10-100 \mathrm{mg} / \mathrm{kg} /$ day); however, they were higher than those used in humans because of a significant up-regulation (3- to 8-fold) of HMG-CoA reductase induced by statin treatment in rodents. ${ }^{18} \mathrm{We}$ also investigated protective efficacy of the drug on survival rates. Simvastatin $(5-40 \mathrm{mg} / \mathrm{kg}$ ) was administered p.o. for five days prior to a single absolute lethal dose of LPS (2x, 2.5x or $3 \mathrm{x} \mathrm{LD}_{50}$ of LPS). The Litchfield\&Wilcoxon procedure ${ }^{17}$ was used to calculate $\mathrm{LD}_{50}$ dose of LPS in the simvastatin pretreated group.

The protection index (PI) was calculated as a ratio of $\mathrm{LD}_{50}$ of LPS in simvastatin pretreated group to $\mathrm{LD}_{50}$ of LPS. We calculated the effective dose $\left(\mathrm{ED}_{50}\right)$ of orally administered simvastatin by the same procedure. ${ }^{17}$ The $\mathrm{ED}_{50}$ is defined as the amount of drug that produces a therapeutic response in $50 \%$ of treated subjects.

Histopathological examination. Tissue sections from rat livers were stained with haematoxylin and eosin (H\&E). Random fields from each specimen were magnified 20x and viewed with an Olympus-2 microscope (Tokyo, Japan).

Semiquantitative analysis. The type, degree and severity of tissue lesions along with the number of inflammatory cells were assessed in tissue samples from each animal and they were counted in six separate visual fields under 40x magnification. The severity of liver lesions (tissue damage score or TDS) was determined according to a 5-point semi-quantitative scale based on the number of inflammatory cells, haemorrhages, edema, and the number of foci involved. Grade "o" indicated normal findings, while grade " 5 " indicated pronounced plasmolysis and cariolysis, along with massive hemorrhagic foci and polymorphonuclear cell (PMNC) infiltration. 
Immunohistochemical determination of apoptosis-regulating Cleaved Caspase-3. Liver samples from control and treated groups were compared $24 \mathrm{~h}$ after the animals were treated. The control group was treated with a single $\mathrm{LD}_{50}$ dose of LPS; the treatment group received simvastatin $(20 \mathrm{mg} / \mathrm{kg})$ for five days prior to administration of a single $\mathrm{LD}_{50}$ dose of LPS. Paraffin-embedded sections of liver tissue were stained with a polyclonal rabbit antibody to cleaved caspase-3 (Thermo Scientific Fischer Ab-4, RB 1197-R7, USA), according to the manufacturer's instructions. Diaminobenzidine tetrahydrochloride was used to develop the antigen-antibody complex, and all slides were counterstained with H\&E, dehydrated, and mounted. Appropriate positive controls were processed in parallel. For each liver section, random visual fields (100x or 200x) were evaluated, and immunopositive cells were assessed for antibody staining (negative, weak, moderate, strong) as a reflection of caspase-3 expression. ${ }^{19}$

Statistical analysis. All data are reported as the mean \pm standard deviation (SD), and groups were compared by non-parametric statistical tests (t-test, Mann-Withney, Kruskal-Wallis rank test). The median lethal dose of endotoxin ( $\mathrm{LD}_{50}$ of LPS), the effective dose $50 \%\left(\mathrm{ED}_{50}\right)$ of simvastatin and the protective index were calculated by the Lichfield and Wilcoxon procedure, ${ }^{17}$ and $95 \%$ confidence intervals were derived. Differences with values of $\mathrm{P}<0.05$ were considered significant.

\section{Results}

Determination of $L D_{50}$ of LPS and protective dose of simvastatin. Table 1 shows that LPS increased lethality of rats in a dose-dependent manner. The $\mathrm{LD}_{50}$ of i.p. LPS was calculated to be 22.15 (95\% CI 16.5-29.1) $\mathrm{mg} / \mathrm{kg}$.
$40 \mathrm{mg} / \mathrm{kg}$ of simvastatin $(\mathrm{p}=0.04)$. All three doses of LPS induced significant hypothermia $\left(<35,5^{\circ}\right)$ compared to baseline body temperature within $6 \mathrm{~h}$ after challenge $(\mathrm{p}<0$, o5). These findings closely predicted lethality within the first 24 hours. Body temperature returned to normal after 24 hours in animals that survived. We did not observe significant changes in body temperature in rats treated with 20 and $40 \mathrm{mg} / \mathrm{kg}$ of simvastatin. Simvastatin alone had no effect on body temperature (data not shown).

Protection index and anti-inflammatory effective dose of simvastatin in endotoxic shock. We established the protective efficacy of orally administered $20 \mathrm{mg} / \mathrm{kg}$ simvastatin against lethal doses of LPS (2x, 2.5x, $\left.3 \mathrm{xD}_{50}\right)$. Simvastatin improved survival up to $67 \%(\mathrm{p}<0,05)$ in animals treated with $2 \mathrm{XLD}_{50}$ of LPS (Table 2). We calculated that the $\mathrm{LD}_{50}$ of LPS increased significantly to $46,34(37,86-56,74) \mathrm{mg} /$ $\mathrm{kg}$ in the simvastatin pretreatment group and determined that the PI $=2.09$.

To test the protective effect of statin against a single lethal dose of LPS $\left(2 \times \mathrm{XD}_{50}\right)$, we pretreated animals with 5,10 , $20,40 \mathrm{mg} / \mathrm{kg}$ of simvastatin. The highest dose $(40 \mathrm{mg} / \mathrm{kg})$ completely prevented mortality (Table 2), while survival obtained with $20 \mathrm{mg} / \mathrm{kg}$ of simvastatin was significantly less $(\mathrm{p}<0,05)$ (Table 2). The $\mathrm{ED}_{50}$ was $14.14(22,41-8,93)$ $\mathrm{mg} / \mathrm{kg}$.

Effects of simvastatin on liver histology in endotoxic shock. Since leukocyte recruitment is a rate-limiting step in endotoxin-induced liver injury, we analyzed hepatic leukocyte infiltration and liver architecture in the randomly selected liver sections. As seen in Figure 1B; a single dose of $\mathrm{LD}_{50}$ of LPS induced severe liver damage characterized

Table 1. Median lethal dose (LD50) of LPS and effect of simvastatin on mortality.

\begin{tabular}{llll}
\hline Simvastatin (mg/kg/day p.o.) & $\begin{array}{l}\text { LPS } \\
(\mathrm{mg} / \mathrm{kg}, \text { i.p) }\end{array}$ & $\begin{array}{l}\text { No. of rats } \\
\text { (dead/total) }\end{array}$ & $\begin{array}{l}\text { LD }_{50} \text { of LPS (95\% CI) } \\
\text { (mg/kg i.p) }\end{array}$ \\
\hline None & 10 & $0 / 6$ & $22.15(16.5-29.1)$ \\
& 20 & $3 / 6$ & \\
\hline 5 & 30 & $4 / 6$ & - \\
10 & $\mathrm{LD}_{50}$ & $3 / 6$ & \\
20 & & $1 / 6$ & \\
40 & & $0 / 6$ & \\
\hline
\end{tabular}

aMale Wistar rats were divided into three groups ( $\mathrm{n}=6$ per group), injected i.p. with LPS $(10,20,30 \mathrm{mg} / \mathrm{kg}$ b.w.) i.p. Survival was measured over the 7 days. The dose of LPS that was lethal to $50 \%$ of the rats $\left(\operatorname{LD}_{50}\right)$ was $22.15 \mathrm{mg} / \mathrm{kg}(95 \% \mathrm{Cl} 16.5-29.1)$. Rats were divided into three groups ( $n=6$ per group) and treated orally with simvastatin $(5,10,20$, or $40 \mathrm{mg} / \mathrm{kg} / \mathrm{day})$ for 5 days and then with a single i.p dose of $L_{P S}\left(\mathrm{LD}_{50}\right)$. Survival of animals was measured over 7 days.

Various doses of simvastatin given prior to LPS challenge resulted in dose-dependent increase in survival. Table 1 shows that complete protection was achieved with 20 and by sinusoidal hyperemia, vasodilatation and prominent perivascular accumulation of PMNCs. Also, it can be seen a few foci of subcapsular hepatocytes necrosis with PMNC 
Table 2. Simvastatin improves survival in rats challenged with lethal doses of LPS. The LD ${ }_{50}$ of LPS in simvastatin group and protective index $(\mathrm{PI})$ for oral simvastatin $(20 \mathrm{mg} / \mathrm{kg})$ was established by a five-day pretreatment regimen. One set of rats was divided into three groups ( $n=6$ per group); the animals were challenged i.p with a single lethal dose of LPS $\left(2 x, 2,5 x\right.$ or $\left.3 x L_{50}\right)$.

\begin{tabular}{|c|c|c|c|c|}
\hline $\begin{array}{l}\text { Simvastatin (mg/kg/ } \\
\text { day, p.o.) }\end{array}$ & $\begin{array}{l}\text { LPS } \\
\text { (mg/kg, i.p.) }\end{array}$ & $\begin{array}{l}\text { No. of rats } \\
\text { (dead/total) }\end{array}$ & $\begin{array}{l}\mathrm{LD}_{50} \text { of LPS }(95 \% \mathrm{CI})(\mathrm{mg} / \\
\mathrm{kg} \text {, i.p.) }\end{array}$ & $\begin{array}{l}\mathrm{PI} / \mathrm{ED}_{50}(95 \% \mathrm{CI}) \\
(\mathrm{mg} / \mathrm{kg}, \mathrm{p.o} .)\end{array}$ \\
\hline 20 & $\begin{array}{l}2 \times \mathrm{LD}_{50} \\
2,5 \times \mathrm{LD}_{50} \\
3 \times \mathrm{LD}_{50}\end{array}$ & $\begin{array}{l}2 / 6 \\
4 / 6 \\
6 / 6 \\
\end{array}$ & $\begin{array}{l}46,34^{\mathrm{a}} \\
(37,86-56,74)\end{array}$ & $2.09^{a}$ \\
\hline $\begin{array}{l}5 \\
10 \\
20 \\
40\end{array}$ & $2 \times \mathrm{LD}_{50}$ & $\begin{array}{l}6 / 6 \\
6 / 6 \\
2 / 6 \\
0 / 6\end{array}$ & - & $\begin{array}{l}14.14 \\
(22,41-8,93)^{b}\end{array}$ \\
\hline
\end{tabular}

a Next, to determine effective dose $\left(E D_{50}\right)$ of orally administered simvastatin, another set of animals was divided into four groups ( $\mathrm{n}=6$ per

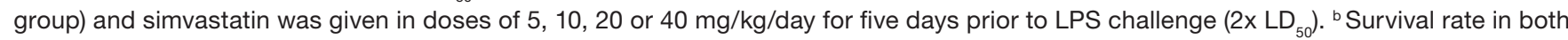

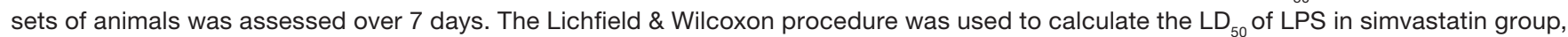
$\mathrm{PI}$ and $\mathrm{ED}_{50}$ of simvastatin.

infiltration. Most of the hepatocytes (> 50\% cells) showed pronounced vacoulisation of cytoplasm and nucleoplasm, and pycnotic nuclei. Severity of liver injury induced by $\mathrm{LD}_{50}$ of LPS is estimated as TDS of $3.67(\mathrm{SD}=0.55)($ Table 3$)$.

Pretreatment with $20 \mathrm{mg} / \mathrm{kg}$ of simvastatin significantly inhibited these pathological changes concomitant with reduction of inflammatory infiltration. (Figure 1C). We noted increased mitotic activity of hepatocytes (mostly with pathological nuclei), vasodilatation and decreased liver damage in sections from animal pretreated with 40 $\mathrm{mg} / \mathrm{kg}$ of simvastatin. The reduction of inflammatory infiltrate was approximately $50 \%$ greater than with $20 \mathrm{mg} /$ $\mathrm{kg}$ of simvastatin, suggesting that the protective and antiinflammatory effects are dose-dependent. Simvastatin (40 $\mathrm{mg} / \mathrm{kg}$ ) significantly decreased TDS compared to that of the untreated group $(p<0.001)$ (Table 3$)$.
Immunohistochemical detection of cleaved caspase-3. Because hepatocellular apoptosis is a hallmark of endotoxininduced liver damage, we assessed liver cell apoptosis in stained tissue sections and measured cleaved caspase-3 immunohistochemically. As expected, we found that the calculated LPS $\mathrm{LD}_{50}$ increased apoptosis of centrilobular hepatocytes, which can be identified by moderate cytoplasmatic staining (Figure 2A and 2B). Moderate nuclear and/ or cytoplasmatic staining of cleaved caspase- 3 was also detected in resident liver macrophages located within the sinusoidal spaces (Kupffer cells). Notably, administration of simvastatin decreased endotoxin-induced apoptosis of macrophages as well as hepatocytic cell death by attenuating expression of cleaved caspase-3. (Figure 2C), which is stained immunohistochemically for cleaved caspase-3, shows only weakly stained immune cells and negative or unstained hepatocytes.

Table 3. Effects of simvastatin on the tissue damage score (TDS) in LPS induced liver injury. Effects of oral simvastatin pretreatment $\left(10,20\right.$ and $40 \mathrm{mg} / \mathrm{kg}$ ) on TDS were evaluated 7 days after a single dose of LPS $_{\left(\mathrm{LD}_{50}\right)}$ ) and compared to TDS in group treated with LPS alone or control group. The TDS was determined in six randomly selected visual fields (40x) from tissue sections of each liver. TDS was graded on a scale of $0-5$, based on the amount of inflammatory cells, hemorrhages and oedema as well as the number of foci involved.

\begin{tabular}{|c|c|c|c|c|c|c|}
\hline \multirow[b]{2}{*}{ Drugs } & \multicolumn{5}{|c|}{ TDS (6 liver samples x 6 sections) } & \multirow[t]{2}{*}{ Values are mean (SD) } \\
\hline & 0 & 1 & 2 & 3 & 4 & \\
\hline Control $^{1}$ & 36 & 0 & 0 & $\mathrm{O}$ & 0 & 0 \\
\hline $\mathrm{LD}_{50} \mathrm{LPS}$ & $\mathrm{O}$ & 0 & 0 & 13 & 23 & $3.67(0.55)^{2}$ \\
\hline Simvastatin, $10 \mathrm{mg} / \mathrm{kg}$ & $\mathrm{O}$ & $\mathrm{O}$ & 12 & 24 & $\mathrm{O}$ & $2.67(0.52)^{3}$ \\
\hline Simvastatin, $20 \mathrm{mg} / \mathrm{kg}$ & $\mathrm{O}$ & 12 & 14 & 10 & $\mathrm{O}$ & $2.00(0.89)^{3,4}$ \\
\hline Simvastatin, $40 \mathrm{mg} / \mathrm{kg}$ & $\mathrm{O}$ & 15 & 21 & 0 & 0 & $1.5(0.55)^{4}$ \\
\hline
\end{tabular}

$\S{ }^{1}$ Saline $(1 \mathrm{~mL} / \mathrm{kg})$. The differences in TDS between groups were statistically analyzed using the Kruskal-Wallis rank test and results were expressed in $X(S D){ }^{2} p<0.001$ versus control, ${ }^{3} p<0.05$ versus control, ${ }^{4} p<0.001$ versus LD $_{50}$ LPS. 

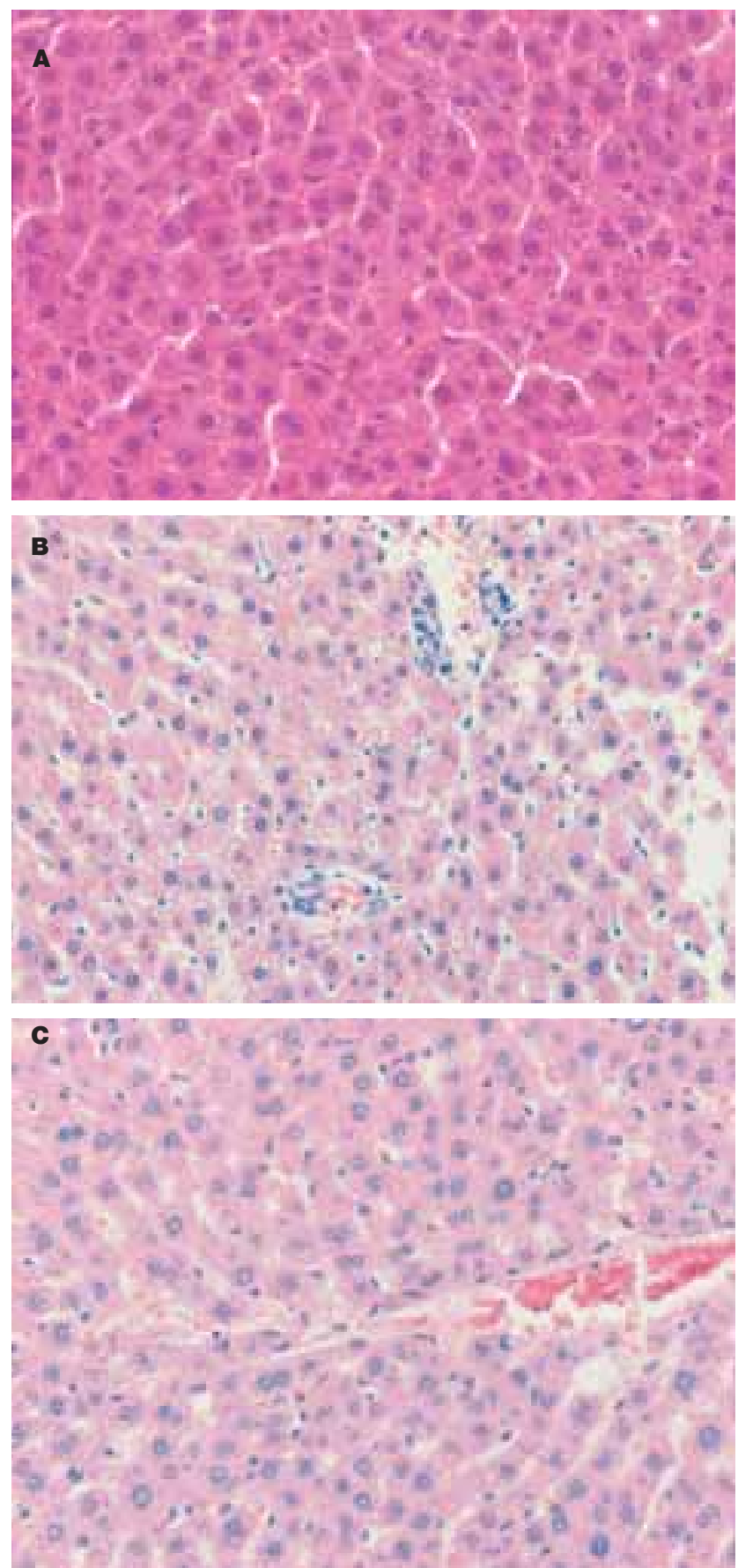

Figure 1. Simvastatin protects against pathological changes in the liver induced by LPS.

Representative section from each group of six rats (haematoxylin and eosin staining, magnification 20x). A = Control (untreated) rat. $B=$ LPS challenged rat $\left(L_{50}\right)$ showing sinusoidal hyperemia, prominent infiltration of PNMC, local necrotic foci, with moderate disorganization of liver architecture. C = Pretreatment with simvastatin $(20 \mathrm{mg} / \mathrm{kg}$, orally $)$ before the single LD $_{50}$ of LPS; note the significant reduction in inflammatory infiltrates compared to $B$.
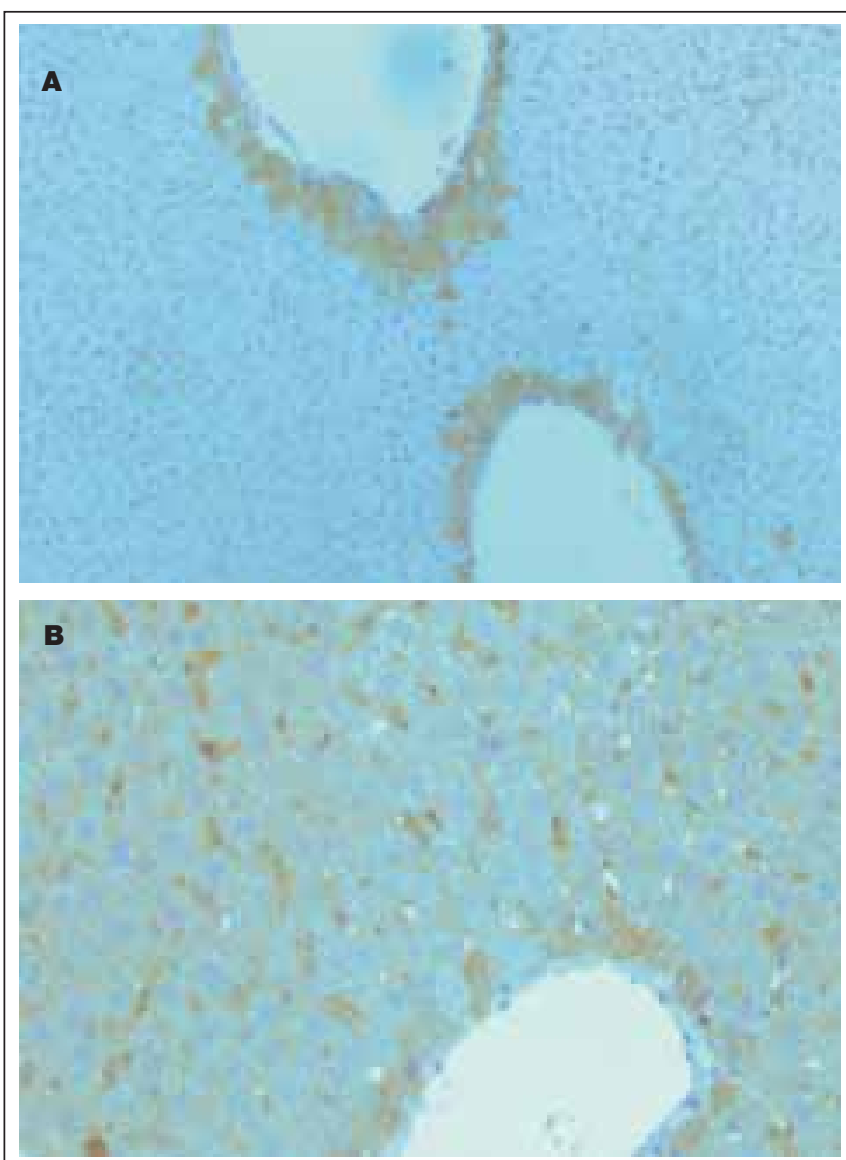

c

Figure 2. Immunohistochemical detection of liver cell apoptosis in endotoxic shock.

A. Cytoplasmatic staining for cleaved caspase- 3 in hepatocytes from rats treated with single LD $_{50}$ of LPS (x10 magnification); B. Nuclear and/or cytoplasmatic staining for cleaved caspase-3 in Kupffer cells from rats treated with single $L_{50}$ of LPS (x20 magnification). C. Weak staining of Kupffer cells and unstained hepatocytes from rats pretreated with simvastatin $20 \mathrm{mg} / \mathrm{kg}$ before the single LD $_{50}$ of LPS (x20 magnification). 


\section{Discussion}

We find that orally administered simvastatin, in doses comparable to those used in clinical practice, significantly improves survival in a rat model of endotoxic shock and protects the animals from endotoxin-induced liver injury. Pretreatment with simvastatin markedly reduced intrahepatic infiltration of leukocytes as well as hepatocellular apoptosis in endotoxemic rats.

Statins have potent anti-inflammatory actions that appear to be independent of their effect on cholesterol metabolism. ${ }^{11,13,15,16}$ These drugs are reported to decrease sepsisinduced mortality, although the protective mechanisms remain elusive. ${ }^{20,21}$ Several studies in a murine model of endotoxic shock suggest that simvastatin improves survival and protects against endotoxin-induced multiple organ injury, including kidney and liver failure. ${ }^{5,7,22}$ Various studies confirm that statins suppress release of proinflammatory cytokines (TNF- $\alpha$, IL-1, IL-6), ${ }^{4,22}$ stimulate production of anti-inflammatory biomarkers (IL-10, NO) ${ }_{5,22}$ and decrease markers of organ injury associated with endotoxic shock. 57,22

Current research indicates that statins may protect against endotoxin-induced hepatotoxicity via a HMG-CoA reductase-dependent mechanism. For example, Slotta et al.7 found that co-administration of mevalonate with simvastatin almost completely reversed the protective effect of the statin on endotoxin-induced liver injury, suggesting participation of HMG-CoA reductase-dependent pathways. HMG-CoA reductase-independent effects of statins on endotoxemic liver injury remain to be documented.

Leukocyte recruitment and extravascular accumulation are key components in both host-defense reactions and in organ injury. Because leukocyte recruitment is an early and rate-limiting step in endotoxin-induced liver injury, ${ }^{8,9}$ we examined the effect of simavastatin on intrahepatic infiltration of leukocytes in animals challenged with sublethal and lethal doses of endotoxin. The results, expressed as TDS, indicate that simvastatin significantly reduced endotoxin-provoked infiltration of leukocytes and deterioration of normal structure in a dose-related manner. This observation extends previous studies that reported attenuation by statins of leukocyte infiltration into the brain, ${ }^{23}$ retina, ${ }^{23}$ heart ${ }^{22}$, and synovium. ${ }^{24}$ The data further indicate that leukocyte accumulation in the liver responds to treatment with statins. These drugs inhibit LFA-1, a key adhesion molecule that influences endotoxin-induced leukocyte recruitment and liver damage by binding to a regulatory site on LFA-1. ${ }^{25}$ Moreover, statins also inhibit a number of critical points in endotoxin-induced leukocyte recruitment and tissue injury. These include the expression of specific adhesion molecules, such as P-selectin ${ }^{8}$ and intercellular adhesion molecule-1, ${ }^{9}$ as well as generation of hepatic chemokines. ${ }^{11}$
Hepatocyte apoptosis is a prominent and important feature in endotoxemic liver injury, and over-production of TNF- $\alpha$ appears to trigger the extrinsic pathway of apoptosis. ${ }^{26}$ These findings are in accord with our previous study, ${ }^{4}$ where we found increased production of TNF- $\alpha$ in endotoxemic rats. Hepatocyte apoptosis may be an end-stage of endotoxin-induced liver injury, but it may also signal early changes in endotoxemic hepatotoxicity. Fouzi and associates $^{27}$ found that activation of a membrane receptor Fas (from superfamily of TNF receptors) causes apoptosis and generates chemokines and inflammation in the liver. Furthermore, endotoxin may trigger apoptosis even before the onset of leukocyte recruitment. ${ }^{28}$

In contrast, inhibition of chemokines and specific adhesion molecules expression decreases endotoxin-induced apoptosis via attenuation of PMNC infiltration. Together, these findings indicate that endotoxin-induced liver injury involves a complex interplay between inflammation, necrosis and apoptosis. In this escalating cascade, necrotic and apoptotic cells also enhance recruitment of leukocytes, while, in turn, accumulating inflammatory cells reinforce further hepatocellular apoptosis. ${ }^{8}$

In this study, we noted a significant increase in hepatocytes with characteristic nuclear morphological hallmarks of programmed cell death, such as nuclear pycnosis and karyorrhexis. These findings mirrored the increase in caspase- 3 activity in the liver. Simvastatin treatment markedly reduced endotoxin-induced increases in caspase-3 activity and apoptosis of liver hepatocytes and macrophages. Slotta et al.7 reported that anti-apoptotic activity of simvastatin was reversed by co-injection of mevalonate. Their results suggest that the protective action of the statin depends upon HMG-CoA reductase regulation of programmed cell death in endotoxemic liver injury.

While we used endotoxin (LPS) to initiate acute, severe inflammation and endotoxic or septic shock, our rat model lacks an infection site commonly seen in clinical cases of endotoxic shock; it uses just one of many ways to activate the immune system. Our technique caused an acute, short-lived activation, not the extended inflammatory state where pro-inflammatory cytokines persist in circulation, as occurs with multiple organ injury. The animal species and the endotoxin dose (rodents are resistant to endotoxin and thus require higher doses than humans), as well as the dose and duration of simvastatin treatment, could also affect the results. ${ }^{29}$

Nonetheless, for this particular model, oral simvastatin exhibits protective and anti-inflammatory effects. It inhibits endotoxin-provoked inflammatory infiltration and deterioration of the liver, including apoptosis of hepatocytes and macrophages, suggesting that therapy with simvastatin or other agents that directly target $\mathrm{HMG}-\mathrm{CoA}$ reductase could protect the liver against inflammation. 
No potential conflict of interest relevant to this article was reported.

\section{References}

1. Gao F,Linhartova L, Johnston AM, Thickett DR. Statins and sepsis. Br J Anaesth 2008;100:288-98.

2. Ando H, Takamura T, Ota T, Nagai Y, Kobayashi K. Cerivastatin improves survival of mice with lipopolysaccharide induced sepsis. J Pharmacol Exp Ther 2000;294:1043-6.

3. Yasuda H, Yuen PS, Hu X, Zhou H, Star RA. Simvastatin improves sepsis-induced mortality and acute kidney injury via renal vascular effects. Kidney Int 2006;69:1535-42.

4. Nežić L, Škrbić R, Dobrić S, Stojiljković MP, Milovanović Z, Jaćević V. et al. Effect of simvastatin on proinflammatory cytokines production in rats during lipopolysaccharide-induced inflammation. Gen Physiol Biophys 2009;Spec No:119-26.

5. Chaudhry MZ, Wang JH, Blankson S, Redmond HP. Statin (cerivastatin) protects mice against sepsis-related death via reduced proinflammatory cytokines and enhanced bacterial clearance. Surg Infect (Larchmt) 2008;9:183-94.

6. Holman JM, Saba TM. Hepatocyte injury during post-operative sepsis: activated neutrophils as potential mediators. J Leukoc Biol 1998;43:193-203.

7. Slotta JE, Laschke MW, Wang Y, Schilling MK, Menger MD, Thorlacius H. Inhibition of HMG-CoA reductase reduces leukocyte recruitment and hepatocyte apoptosis in endotoxin-induced liver injury. J Investig Med 2009;5:645-9.

8. Klintman D, Li X, Thorlacius H. Important role of P-selectin for leukocyte recruitment, hepatocellular injury, and apoptosis in endotoxemic mice. Clin Diagn Lab Immunol 2004;11:56-62.

9. Klintman D, Schramm R, Menger MD. Leukocyte recruitment in hepatic injury: selectin-mediated leukocyte rolling is a prerequisite for CD18-dependent firm adhesion. J Hepatol 2002;36:53-9.

10. Wong J, Johnston B, Lee SS, Bullared DC, Smith CV, Beaudet AL. et al. A minimal role for selectins in the recruitment of leukocytes into the inflamed liver microvasculature. J Clin Invest 1997;99:2782-90.

11. Li X, Klintman D, Weitz-Schmidt G, Schramm R, Thoralacius. Lymphocyte function antigen-1 mediates leukocyte adhesion and subsequent liver damage in endotoxemic mice. Br J Pharmacol 2004;141:709-16.

12. Takemoto M, Liao JK. Pleiotropic effects of 3-hydroxy-3-methylglutaryl coenzyme a reductase inhibitors. Arterioscler Thromb Vasc Biol 2001; 21:1712-9.

13. Pierre-Paul D, Gahtan V. Noncholesterol-lowering effects of statins. Vasc Endovasc Surg 2003; 37:301-13.

14. Grundy SM, Cleeman JI, Merz CN, Brewer HB Jr, Clark IT, Hunninghake DB. et al. Implications of recent clinical trials for the National Cholesterol Education Program Adult Treatment Panel III guidelines, Arterioscler Thromb Vasc Biol 2004;24:149-61.

15. Falagas ME, Makris GC, Matthaiou DK, Rafailidis PI. Statins for infection and sepsis: a systematic review of the clinical evidence, J. Antimicrob.Chemother 2008;61:774-85.

16. Merx MW, Liehn EA, Graf J, van de Sandt A, Schaltenbrand M, Schrader J. et al. Statin treatment after onset of sepsis in a mu- rine model improves survival. Circulation 2005;112:117-24.

17. Litchfield JT, Wilcoxon F. A simplified method of evaluating dose effective experiments. J Pharmacol Exp Ther 1949;96:99-113.

18. Garip S, Severcan F. Determination of simvastatin-induced changes in bone composition and structure by Fourier transform infrared spectroscopy in rat animal model. J Pharma Biomed Analysis 2010;52:580-8.

19. The Human Protein Atlas. [home page on the Internet]: Knut \& Alice Wallenberg foundation. Available from http://www.proteinatlas.org/ ENSGooooo164305/normal

20. Dobesh PP, Klepser DG, McGuire TR, Morgan CW, Olsen KM. Reduction in mortality associated with statin therapy in patients with severe sepsis. Pharmacotherapy 2009;29:621-30.

21. Mortensen EM, Restrepo MI, Anzueto A, Pugh J. The effect of prior statin use on 30-day mortality for patients hospitalized with community-acquired pneumonia. Respir Res 2005;6:82-9.

22. Chung HC, Lee RP, Wu WT, Liao KW, Hsu N, Hsu BG. Fluvastatin ameliorates endotoxin induced multiple organ failure in conscious rats. Resuscitation 2007; 74:166-74.

23. Weitz-Schmidt G. Statins as anti-inflammatory agents. Trends Pharmacol Sci 2002;23:482-6.

24. Naidu BV, Woolley SM, Farivar AS, Thomas R, Fraga C, Mulligan MS. Simvastatin ameliorates injury in an experimental model of lung ischemia-reperfusion. J Thorac Cardiovasc Surg 2003;126:482-9.

25. Weitz-Schmidt G, Welzenbach K, Dawson J, Kallen J. Improved lymphocyte function-associated antigen-1 (LFA-1) inhibition by statin derivatives: molecular basis determined by $\mathrm{x}$-ray analysis and monitoring of LFA-1 conformational changes in vitro and ex vivo. J Biol Chem 2004;279(45):46764-71.

26. Mahidhara R, Billiar TR. Apoptosis in sepsis. Crit Care Med 2000;28:N105-13.

27. Faouzi S, Burckhardt BE, Hanson JC, Campe CB, Schrum LW, Rippe RA. et al. Anti-Fas induces hepatic chemokines and promotes inflammation by an NF- $\kappa$ B-independent, caspase-3-dependent pathway. J Biol Chem 2001;276,49077-82.

28. Lawson JA, Fisher MA, Simmons CA, Farhood A, Jaeschke H. Parenchymal cell apoptosis as a signal for sinusoidal sequestration and transendothelial migration of neutrophils in murine models of endotoxin and Fas-antibody-induced liver injury. Hepatology 1998;28:761-7.

29. Poli de Figueiredo LF, Garrido AG Nakagawa N, Sannomiya P. Experimental models of sepsis and their clinical relevance. Shock 2008; 30, Suppl 1:53-9. 